\title{
Metastable freezing: A new method for the estimation of salinity in aqueous fluid inclusions
}

\author{
Jamie J. Wilkinson
}

London Centre for Ore Deposits and Exploration (LODE), Department of Earth Sciences, Natural History Museum, Cromwell Road, London SW7 5BD, UK

and

Department of Earth Science and Engineering, Imperial College London, South Kensington

Campus, Exhibition Road, London SW7 2AZ, UK

\begin{abstract}
On cooling during microthermometry, fluid inclusions invariably supercool before freezing under disequilibrium (metastable) conditions to form ice and hydrates. Measurements of fluid inclusions from the Irish $\mathrm{Zn}-\mathrm{Pb}$ hydrothermal system reveal a strong linear correlation $\left(\mathrm{R}^{2}=\right.$ 0.968 ) between final ice melting temperature $\left(\mathrm{T}_{\mathrm{mI}}\right)$ and metastable freezing temperature $\left(\mathrm{T}_{\mathrm{mf}}\right)$ of the form:

$$
\mathrm{T}_{\mathrm{mI}}=0.563 \mathrm{~T}_{\mathrm{mf}}+22.7(+1.5 /-3.5)
$$

The relationship is shown to be independent of heating-freezing stage model, host mineral, and largely of inclusion size, but is affected by the presence of $\mathrm{CO}_{2}$ and by cooling rate. The correlation shows that metastable freezing is predictable and in fact, in small droplets of pure solution, occurs at a well-defined, salinity-dependent temperature referred to as the homogeneous freezing point. This relationship allows salinity to be estimated in fluid inclusions where the optical recognition of final ice melting is not possible due to small inclusion size or cloudy samples, or where inclusions go into a metastable, vapor-absent, state because of collapse of the bubble on freezing. Using a cooling rate of $\sim 50^{\circ} \mathrm{C} / \mathrm{min}$, inclusion salinity is given by:
\end{abstract}

$$
\text { Salinity }(\mathrm{wt} \% \mathrm{NaCl} \text { equivalent })=-69.7-2.617 \mathrm{~T}_{\mathrm{mf}}-0.02603 \mathrm{~T}_{\mathrm{mf}}{ }^{2}-0.0000994 \mathrm{~T}_{\mathrm{mf}}{ }^{3}
$$

The homogeneous freezing point is controlled by an equilibrium thermodynamic property related to the activity of water. In small droplets of pure solution, as approximated by fluid inclusions, freezing will occur when the water activity is 0.305 above that of the stable ice melting condition at the same temperature, independent of solute type. "Early" metastable freezing, at a temperature above the homogeneous freezing point may occur in very large inclusions, or those containing "seed" particles or $\mathrm{CO}_{2}$. In such cases, the salinity will be underestimated by the equation above.

\section{Introduction}

Fluid inclusion microthermometry has been long established as the only direct method for constraining the properties of paleofluids in the Earth's crust (e.g. Roedder, 1967a). In particular, the ability to constrain fluid density, trapping temperature and pressure, solute and volatile contents has provided many important tests of genetic models for hydrothermal ore formation (Roedder and Bodnar, 1997). It is also the basis for the more advanced techniques such as laser ablation ICP-MS that are providing fundamental new insights into metal transport 
and deposition from ore-forming fluids (e.g. Audetat et al., 1998, 2008; Heinrich et al., 1999; Ulrich et al., 1999; Wilkinson et al., 2009; Kouzmanov and Pokrovski, 2012).

The basic principles of microthermometry by which fluid inclusions are investigated using a heating-freezing stage are well established (e.g. Roedder, 1984; Shepherd et al., 1985). Total homogenisation temperatures, typically by liquid-vapor homogenisation, can provide minimum constraints on trapping pressure and temperature. Measurements of halite, hydrate and ice melting temperatures can be used to estimate fluid salinity, assuming simple model systems such as $\mathrm{NaCl}-\mathrm{H}_{2} \mathrm{O}$ (Roedder, 1984; Wilkinson, 2001; Bodnar et al., 2014). Multiple solid phase melting temperatures can also be combined to interpret compositions and fluid evolution processes in ternary compositional space, such as $\mathrm{NaCl}-\mathrm{KCl}-\mathrm{H}_{2} \mathrm{O}$ or $\mathrm{H}_{2} \mathrm{O}-\mathrm{FeCl}_{2}-\mathrm{NaCl}$ in porphyry systems (e.g. Bloom, 1981; Lecumberri Sanchez et al., 2015); or $\mathrm{NaCl}_{-} \mathrm{CaCl}_{2}-\mathrm{H}_{2} \mathrm{O}$ in IOCG (Xu, 2000) and carbonate-replacement SEDEX deposits (Wilkinson, 2010).

The determination of fluid salinity is particularly important because of the conservative nature of halogens, and particularly chloride, in crustal fluids. As a result, salinity (chlorinity) is one of the most useful general parameter for identifying fluid mixing processes, and allows quantification of mixing proportions. Mixing is a critical process in many ore-forming systems and is probably one of the most important controls of ore mineral deposition (Skinner, 1997). Fluid salinity is also intrinsically related to base metal solubility in many fluids (Yardley, 2005) and so is a master variable in metal transport. Finally, fluid salinity can be quite diagnostic of fluid source with the most saline, halite-bearing inclusions being almost exclusively magmatic in origin, saline (but halite-undersaturated) inclusions with elevated $\mathrm{CaCl}_{2}$ being typical of basinal brines, and very low (near zero) salinity inclusions being likely to represent meteoric fluids (Wilkinson, 2001; Bodnar et al., 2014).

Despite their importance, salinity determinations in fluid inclusions can be difficult in many samples because of: (i) poor optical resolution in cloudy or semi-transparent minerals (e.g. calcite); (ii) difficulties in resolving final ice melting temperature, particularly in low salinity fluids where the refractive index contrast between fluid and ice is small; or (iii) because of extremely small inclusion size. The typical lower limit for determination of accurate ice melting temperatures is around 4-5 microns. This can result in studies only reporting homogenisation temperature data, which are of limited use on their own.

Here, an alternative approach is presented for the estimation of salinity in aqueous fluid inclusions that are undersaturated with salt at ambient temperature. This method utilises the fact that the degree of supercooling required to freeze fluid inclusions (metastable freezing) is directly related to the dissolved salt content. This phenomenon, of predictable homogeneous nucleation of ice in supercooled systems, is well studied primarily through its relevance to cloud formation (e.g. see http://www1.lsbu.ac.uk/ water/phase_anomalies.html), so there is an excellent theoretical foundation. It is shown that metastable freezing temperatures have a very good, near linear correlation with final ice melting temperatures over a wide range of fluid salinity. Thus, recording metastable freezing, easily recognised in even small ( $\geq 1 \mu \mathrm{m})$ or optically-compromised inclusions by the contraction or complete collapse of the vapor bubble, allows salinity to be estimated with a reasonable degree of accuracy and precision. Although this will not replace traditional methods utilising optical observation of final ice melting, it does present a viable alternative where such observations are not possible.

\section{Materials and Methods}

Microthermometric data for this investigation were collected using three different heatingfreezing stages (Linkam THM600, THMS600, MDS600) over almost 18 years from December 1996 to October 2014. The samples used all derive from the Irish Zn-Pb orefield (Wilkinson, 2010, 2014) and include five host mineral phases (calcite, dolomite, barite, sphalerite and quartz) from the ore deposits and regional carbonate cements. All inclusions studied were aqueous, two-phase, liquid-vapor inclusions, $1.5-130 \mu \mathrm{m}$ in maximum dimension (median $=8.4$ 
$\mu \mathrm{m})$, with a small proportion of vapor at room temperature ( $\sim 5 \%$ by volume). The vast majority are considered to be primary based on standard criteria (e.g. Roedder, 1984) but some secondary inclusions are also included. For the purposes of this study, the relative timing of trapping is not important. A minority of the inclusions with relatively high liquid-vapor homogenisation temperatures $\left(>240^{\circ} \mathrm{C}\right)$ contained elevated $\mathrm{CO}_{2}$ as indicated by the formation of clathrate on cooling (Everett et al., 1999).

Stages were calibrated using the same synthetic $\mathrm{H}_{2} \mathrm{O}-\mathrm{CO}_{2}$ inclusion throughout, with calibration points at the triple point of $\mathrm{CO}_{2}\left(-56.6^{\circ} \mathrm{C}\right)$, clathrate melting $\left(10.0^{\circ} \mathrm{C}\right), \mathrm{CO}_{2}$ homogenisation (to vapor, $30.6^{\circ} \mathrm{C}$ ) and liquid-vapor homogenisation $\left(294.0^{\circ} \mathrm{C}\right.$ ). Measurement precision is $\pm 0.1^{\circ} \mathrm{C}$ (excluding metastable freezing; see below) and accuracy is estimated at $\pm 0.2^{\circ} \mathrm{C}$ at -60 to $+30^{\circ} \mathrm{C}$ and $\pm 0.5^{\circ} \mathrm{C}$ at higher temperatures.

Inclusions were typically cooled from near $0^{\circ} \mathrm{C}$ (usually after a prior freezing run) using an uncontrolled cooling rate governed by the Linkam LNP93 liquid nitrogen pumping system (Fig. 1). This achieved an initial cooling rate of $\sim 100^{\circ} \mathrm{C} / \mathrm{min}$ decreasing to $\sim 50^{\circ} \mathrm{C} / \mathrm{min}$ at low temperatures, with an overall rate of $\sim 60^{\circ} \mathrm{C} / \mathrm{min}$. Metastable freezing temperatures $\left(\mathrm{T}_{\mathrm{mf}}\right)$ were recorded at the point of vapor bubble contraction or collapse. This obviously occurs at quite a fast cooling rate so that there is an inherent error associated with its measurement. After freezing, inclusions were heated at controlled rates of $30^{\circ} \mathrm{C} / \mathrm{min}$ to $0.2^{\circ} \mathrm{C} / \mathrm{min}$ to the point of final ice melting $\left(\mathrm{T}_{\mathrm{mI}}\right)$. The phase transition itself was recorded at heating rates of $<0.5^{\circ} \mathrm{C} / \mathrm{min}$ to ensure accurate and precise measurement. In approximately $10 \%$ of cases, final ice melting measurements were repeated in order to ensure data quality and were nearly always within $\pm 0.1^{\circ} \mathrm{C}$.

In order to assess measurement precision for metastable freezing and to evaluate any impact of cooling rate on this behavior, four experiments were carried out in which the same inclusion (quartz-hosted, 5 micron, equant, subhedral shape) was frozen ten times in succession. The four experiments were: (i) free cooling from $25^{\circ} \mathrm{C}$; (ii) free cooling from $0^{\circ} \mathrm{C}$; (iii) cooling from $0^{\circ} \mathrm{C}$ at $50^{\circ} \mathrm{C} / \mathrm{min}$; and (iv) cooling from $0^{\circ} \mathrm{C}$ at $20^{\circ} \mathrm{C} / \mathrm{min}$. The measured final ice melting temperature for this test inclusion was $-0.9^{\circ} \mathrm{C}$.

The observed relationships between $\mathrm{T}_{\mathrm{mf}}$ and $\mathrm{T}_{\mathrm{mI}}$ were considered in relation to a range of variables to assess the sensitivity of metastable freezing to these parameters: (i) host mineral; (ii) inclusion size; (iii) presence of $\mathrm{CO}_{2}$; (iv) heating-freezing stage model; and (v) cooling rate.

\section{Results}

331 inclusions yielded both metastable freezing and final ice melting temperatures and these data form the basis of the analysis below. Of these, a subset of 148 had inclusion maximum dimension recorded and these were used for the evaluation of potential size effects. 25 inclusions were observed to form clathrate on cooling and these were used to gauge the possible effect of $\mathrm{CO}_{2}$ presence on metastable freezing temperature. The full dataset was also subdivided into results obtained from the three different heating-freezing stage models in order to check there was no bias derived from this source. Finally, forty measurements of $\mathrm{T}_{\mathrm{mf}}$ for the same test inclusion were used to evaluate the effect of cooling rate and were compared with a predicted $\mathrm{T}_{\mathrm{mf}}$ based on the results from the full study of natural inclusions.

Final ice melting temperatures ranged from -0.3 to $-36.0^{\circ} \mathrm{C}$ (median $=-12.4^{\circ} \mathrm{C}$ ), with results below $-21.2^{\circ} \mathrm{C}$ derived from very saline inclusions with elevated $\mathrm{CaCl}_{2}$ content (Wilkinson, 2010). This wide range reflects the diversity of fluid types in the Irish ore field and also the spread in salinities observed in the ore forming stages that has been attributed to fluid mixing (Samson and Russell, 1987; Wilkinson et al., 2005). Metastable freezing temperatures ranged from -39.8 to $-94.4^{\circ} \mathrm{C}$ (median $=-62.3^{\circ} \mathrm{C}$ ) with the majority in the range -45 to $-85^{\circ} \mathrm{C}$.

Overall, the $\mathrm{T}_{\mathrm{mf}}$ and $\mathrm{T}_{\mathrm{ml}}$ results display a very strong linear correlation (Fig. 2) with a correlation coefficient $\left(\mathrm{R}^{2}\right)$ for the entire dataset of 0.968 (Table 1). To fit the data, a robust least-squares regression methodology (least median of squares method) was used that down- 
weights the influence of samples with large residuals (Rousseeuw and Leroy, 1987) as implemented in the ioGas software package (Reflex http://reflexnow.com/iogas/).

\section{Host mineral effects}

A wide variation in inclusion salinity is observed for all host minerals, reflecting their growth in most stages of the paragenesis and during fluid mixing. With respect to the $\mathrm{T}_{\mathrm{mf}}-\mathrm{T}_{\mathrm{mI}}$ correlation, there is no clear, host mineral-related deviation from the best-fit line (Fig. 3) and gradient and intercept parameters are within error (Table 1). However, it could be argued that there is a slight bias towards early metastable freezing for dolomite-hosted inclusions which display relatively large mean and median residuals of $-0.91^{\circ} \mathrm{C}$ and $-0.36^{\circ} \mathrm{C}$ respectively (Table 1 ). The cause of this is uncertain; one possibility is a tendency for such inclusions to more frequently contain seed particles allowing earlier ice nucleation.

\section{Inclusion size effects}

It is possible that inclusion size could have an effect on metastable freezing with anecdotal evidence suggesting that larger inclusions might freeze more easily. Visual inspection of the results, plotted in five maximum inclusion dimension bins of equal population size (0-6.3, 6.38.3, 8.3-12.0, 12.0-19.7 and 19.7-130 mm), shows no significant bias (Fig. 4). Robust regressions of each inclusion size subset produce virtually the same correlation parameters (Table 1), although a weak trend toward "early" freezing in larger inclusions is indicated by more negative mean residuals in the larger inclusion size groups. This trend is largely controlled by sphaleritehosted inclusions that tend to be the largest. In addition, the smallest size category is unusual in that it displays a positive mean residual value (Table 1), indicating a bias toward "late" freezing. A tendency for smaller inclusions to display lower $\mathrm{T}_{\mathrm{mf}}$ may well be analogous to the behavior of very small water droplets $(<9 \mu \mathrm{m})$ which can sustain greater degrees of supercooling (as low as $-46^{\circ} \mathrm{C}$ for milliseconds) than larger drops (Sellberg et al., 2014).

\section{Effect of $\mathrm{CO}_{2}$ presence}

Evaluation of the effect of $\mathrm{CO}_{2}$ on metastable freezing is hindered by the limited number of $\mathrm{CO}_{2}$ bearing inclusions observed. Although clathrate formation affects final ice melting temperatures by locking up water and enhancing the salinity of the coexisting aqueous phase, this would just shift a datapoint down the correlation line if the same $\mathrm{T}_{\mathrm{mI}}-\mathrm{T}_{\mathrm{mf}}$ relationship applied because metastable freezing invariably occurs after clathration. Thus, the salinity would be overestimated by metastable freezing but this would also apply to the salinity estimate from final ice melting. However, consideration of the behavior of the $\mathrm{CO}_{2}$-bearing inclusions shows that results are biased to below and to the right of the best-fit line (Fig. 5). Consequently, it is suggested that there is a tendency for $\mathrm{CO}_{2}$ to reduce the amount of supercooling required to nucleate ice, perhaps because the earlier-formed clathrate provides a nucleation template (heterogeneous nucleation). Excluding the $\mathrm{CO}_{2}$-bearing inclusion data from the total dataset has negligible effect on the best-fit parameters, with just a minor reduction in the negative mean residual value (Table 1).

\section{Heating-freezing stage model}

The three Linkam stages used during the course of data collection vary slightly in their geometry but all work in the same basic way with a silver heating block that can be cooled by 
liquid nitrogen flow, upon which sits an XY-controllable sample holder. Calibration curves for the stages, used to correct for the small difference in temperature between the platinum thermocouple mounted in the block and the sample itself, vary between the stages and over time. However, regular calibration on an approximately 6 monthly basis, ensured that recorded temperatures remained accurate at all times, irrespective of the stage used.

Breaking the data down into the stage type used shows no obvious bias in the results (Fig. 6). The determined slope and intercept parameters for the best-fit lines for data collected on the two newer stages (THMS600 and MDS600) differ by a small amount, only just outside the standard errors. The oldest stage (THM600) yields a slightly steeper slope and higher intercept (Table 1$)$ but this is considered to be due to the limited number of datapoints available $(n=19)$ and because they are clustered at either end of the data distribution so the fit is not well constrained.

\section{Cooling rate effects}

Cooling rate is perhaps one of the most likely parameters to influence metastable freezing relationships. It is known that supercooling increases with cooling rate for water (Mullin, 2001) and there is also an inevitable thermal equilibration offset between recorded $\mathrm{T}_{\mathrm{mf}}$ and the actual temperature at the inclusion when it freezes in a sample undergoing rapid cooling. This offset might be expected to decrease as cooling rates are decreased, thereby changing the nature of the $\mathrm{T}_{\mathrm{mf}}-\mathrm{T}_{\mathrm{mI}}$ relationship. Notwithstanding this, the thermal masses of the Linkam stages (heating block and sample holders) are small and thermal equilibration rates are clearly very fast as evidenced by the virtually immediate response of an inclusion to a small step in temperature when close to a phase change such as final ice melting or $\mathrm{CO}_{2}$ phase homogenisation.

The metastable freezing temperature for the same inclusion when measured multiple (10) times was found to be quite reproducible, with relative standard deviations of 1.9, 1.2, 0.9 and $1.5 \%$ for the four experiments performed. However, cooling rate clearly has an effect on $\mathrm{T}_{\mathrm{mf}}$ with free cooling from ambient (Experiment 1) yielding the lowest mean temperature (-42.7) and cooling from $0^{\circ} \mathrm{C}$ at $20^{\circ} \mathrm{C} / \mathrm{min}$ (Experiment 4) yielding the highest mean temperature ($39.0^{\circ} \mathrm{C}$ ). Thus, there is a loose correlation between the parameters with higher cooling rates tending to shift $\mathrm{T}_{\mathrm{mf}}$ slightly lower. This is in agreement with the known behavior of pure water.

There is a suggestion of systematic drift in some of the data, such as progressive lowering of $\mathrm{T}_{\mathrm{mf}}$ through the majority of the measurements made in Experiment 1 and increase in $\mathrm{T}_{\mathrm{mf}}$ during the cycles in experiment 4 (Fig. 7). The reasons for these trends are unclear. Progressive cooling of the heating-freezing stage and air within the sample chamber is likely during a series of experiments, meaning that later runs may have experienced a slightly precooled environment. This would be expected to yield initially lower $\mathrm{T}_{\mathrm{mf}}$ values, due to a greater initial differential between sample temperature and temperature sensor. Any such differential would be expected to decrease slightly in later cycles and so a gradual increase in $\mathrm{T}_{\mathrm{mf}}$ might be expected, as observed in Experiment 4. However, the liquid nitrogen pump was run for 10 minutes prior to starting the series of experiments in order to minimise such an effect. Furthermore, Experiment 4 was run at the end of the sequence, with the lowest cooling rate, both of which would be expected to eliminate this potential artefact. Consequently, a satisfactory explanation for this behavior is currently lacking.

The most consistent results were obtained for stable, high cooling rate conditions (cooling from $0^{\circ} \mathrm{C}$ at $50^{\circ} \mathrm{C} / \mathrm{min}$ ). Almost identical data were recorded for free cooling from $0^{\circ} \mathrm{C}$ (Fig. 7), which would equate to a cooling rate of $\sim 100^{\circ} \mathrm{C} / \mathrm{min}$ in the interval between $0^{\circ} \mathrm{C}$ and metastable freezing for the test inclusion $\left(-41.1 \pm 1.5^{\circ} \mathrm{C}, 1 \sigma\right.$, all data; see Fig. 1$)$.

The predicted $\mathrm{T}_{\mathrm{mf}}$ for the test inclusion based on the best-fit regression of all the data reported in this study is $-41.9^{\circ} \mathrm{C}$. Comparison between this and the data obtained from the four cooling rate experiments (Fig. 8) shows that the best agreement is with Experiment 2 which involved free cooling from $0^{\circ} \mathrm{C}$. This is perhaps unsurprising given that this was the normal 
procedure adopted in the collection of the natural inclusion data. The mean and median $\mathrm{T}_{\mathrm{mf}}$ data for Experiments 1,2 and 3 are all within $\pm 1^{\circ} \mathrm{C}$ of this value indicating that the sensitivity to cooling rate is small in the range $50-100^{\circ} \mathrm{C} / \mathrm{min}$. However, the marked shift to higher $\mathrm{T}_{\mathrm{mf}}$ values in the slower cooling rate experiment (Experiment 4) would result in a significant underestimate of $\mathrm{T}_{\mathrm{ml}}$, and therefore salinity, if the $\mathrm{T}_{\mathrm{fm}}-\mathrm{T}_{\mathrm{ml}}$ relationship discussed here was applied.

\section{Discussion}

\section{Behavior of supercooled aqueous solutions}

It has been shown that there is a well-defined linear relationship between metastable freezing temperatures and final ice melting temperatures in aqueous fluid inclusions dominated by $\mathrm{NaCl}\left(-\mathrm{CaCl}_{2}\right)$. No significant bias was observed in terms of host mineral, inclusion size or the type of heating-freezing stage used so that the relationship is relatively robust for a range of variables. The observed upper limit of metastable freezing for very dilute inclusions is consistent with the homogeneous freezing point (or limit of supercooling) for pure water in micron-sized droplets which is at $\sim-38^{\circ} \mathrm{C}$ (Koop et al., 2000). Greater degrees of supercooling of water require elevated pressure, smaller droplet size or presence of dissolved salts (Mullin, 2001).

The homogeneous freezing point of salt solutions is lowered at approximately twice the rate that the freezing point depression is lowered (Kanno et al., 2004), a relationship that is duplicated here (Fig. 9). Furthermore, the homogeneous freezing point (for a given solution) is the lowest temperature a slowly cooled solution can reach before crystallizing, and this can only be approached when small quantities of high purity solution are used (Toner et al., 2014). As a result, one would predict a scatter of data on the high $\mathrm{T}_{\mathrm{mf}}$ side of the homogeneous freezing point curve and a fairly sharp cut-off on the low side, exactly as is observed in the data (Fig. 9). Consequently, the inclusions are behaving in a predictable manner, consistent with the established theory of supercooled aqueous solutions (e.g. MacKenzie et al., 1977).

In general, supercooling is greater in solutions containing salts of divalent cations such as $\mathrm{CaCl}_{2}$ and $\mathrm{MgCl}_{2}$ because these more highly charged ions with smaller ionic radii tend to increase electrostatic interactions in solution, and thereby increase viscosity (Toner et al., 2014). In the hydrothermal fluids studied here, as in many crustal fluids (but excluding magmatic brines), there is a general increase in $\mathrm{CaCl}_{2}$ content with increasing salinity (Yardley, 2005; Wilkinson, 2010). However, there is no discernible shift to unexpectedly high degrees of supercooling in more saline inclusions, including those known to contain unusually high $\mathrm{CaCl}_{2}$, so that any such effect does not appear to be significant.

Interestingly, homogeneous freezing occurs when the water activity in the metastable salt solution is 0.305 higher than would be the case for a stable salt solution on the ice liquidus at the same temperature (i.e. if metastability did not occur), independent of the nature of the solute (Fig. 10; Koop et al., 2000). This indicates that the kinetic (non-equilibrium) ice nucleation process is driven entirely by the thermodynamic (equilibrium) quantity of this difference in water activity. Thus, the metastable freezing temperature is actually a measure of water activity (which decreases with increasing salinity) and should be predictable theoretically from an ion interaction model without having to rely on an empirical relationship such as that derived here.

\section{Application of the metastable freezing method for estimation of salinity}

There are a number of practical implications of the features noted above. For the reasons discussed, early freezing, prior to the homogeneous freezing point limit, is the main cause of 
scatter in the data reported, reflected by the mean residuals which tend to be negative for most data subsets (Table 1). Consequently, if this method is used to estimate salinity, the most likely error is underestimation of the freezing point depression and therefore also salinity. The results suggest that the presence of $\mathrm{CO}_{2}$ and large inclusion size may enhance this effect. However, the behavior is probably rather unpredictable, linked to a range of factors that impact ice nucleation (e.g. presence of "seed" particles). At the present time, the proposed method is not recommended for $\mathrm{CO}_{2}$-bearing inclusions, not least because it, like measurement of final ice melting, will be compromised by the effects of clathrate formation on $\mathrm{T}_{\mathrm{mI}}$.

As expected, cooling rate influences metastable freezing behavior, so that for the regression proposed here to be applied a similar cooling rate should be used. It is considered that fixed rate cooling from $0^{\circ} \mathrm{C}$ at $50^{\circ} \mathrm{C} / \mathrm{min}$ is optimal because this appears to minimise the variance of replicate measurements (Figs. 7, 8). Nonetheless, free (variable rate) cooling will not introduce any significant bias because, at least on the Linkam stages, this method delivers cooling rates across the entire temperature interval of metastable freezing of close to $50^{\circ} \mathrm{C} / \mathrm{min}$ (Fig. 1).

The proposed relationship between metastable freezing and final ice melting temperatures is given by:

$$
\mathrm{T}_{\mathrm{mI}}=0.563 \mathrm{~T}_{\mathrm{mf}}+22.7(+1.5 /-3.5)
$$

where the quoted uncertainty in derived $\mathrm{T}_{\mathrm{mI}}$ is a relatively pessimistic one based on the $10^{\text {th }}$ and $90^{\text {th }}$ percentile values of the calculated residuals in $\mathrm{T}_{\mathrm{mI}}$ predicted by the equation for the dataset presented. The uncertainty is larger on the negative (greater freezing point depression) side due to the "early" freezing phenomenon; if this occurs, salinity will be underestimated. Using the ice liquidus equation of Bodnar (1993), the relationship translates to:

$$
\begin{aligned}
& \text { Salinity }(\mathrm{wt} \% \mathrm{NaCl} \text { equivalent })= \\
& -69.7-2.617 \mathrm{~T}_{\mathrm{mf}}-0.02603 \mathrm{~T}_{\mathrm{mf}}{ }^{2}-0.0000994 \mathrm{~T}_{\mathrm{mf}}{ }^{3} .
\end{aligned}
$$

The uncertainty in salinity that derives from this depends on where in the salinity range an inclusion lies but, for an intermediate salinity, it would be approximately $+3.2 /-1.6 \mathrm{wt} \% \mathrm{NaCl}$ equivalent.

Using the standard deviation for the replicate measurements collected in the cooling rate experiments for the recommended experimental conditions only (Experiments 2 and 3,10 $=0.5^{\circ} \mathrm{C}, \mathrm{n}=20$ ), and propagating this with the standard errors derived from the regression best fit (Table 1), an uncertainty of $\pm 0.4 \mathrm{wt} \% \mathrm{NaCl}$ equivalent is obtained. This applies across the whole range of metastable freezing temperatures. Consequently, if early metastable freezing can be excluded, or minimised, the algorithm can make quite precise predictions of inclusion salinity.

An alternative calibration of the $\mathrm{T}_{\mathrm{mf}}-\mathrm{T}_{\mathrm{mI}}$ relationship for other heating-freezing stages or cooling rates could of course be derived. This would be particularly important if the method was to be applied using a gas-flow (USGS-type) stage that has a different cooling mechanism and can yield higher cooling rates. However, it is suggested that the relationship proposed here should hold for any microthermometry system as long as a cooling rate of approximately $50^{\circ} \mathrm{C} / \mathrm{min}$ is used and inclusions are frozen using a pre-cooled stage, starting near $0^{\circ} \mathrm{C}$.

The method presented here is applicable for any aqueous inclusion for which $\mathrm{NaCl}$ equivalent salinity can realistically be determined, including compositions within the $\mathrm{NaCl}-\mathrm{CaCl}_{2}$ system calculated as $\mathrm{NaCl}$ equivalent. However, inclusions that are halite-saturated at ambient temperature are excluded. The salinity of aqueous inclusions that show final ice melting at the eutectic, and have hydrohalite as the final solid phase (e.g. Gleeson et al., 2000), is likely to be reasonably approximated by the algorithm. Because of the solute-independent nature of the metastability (Fig. 10) it is also valid for inclusions that trapped fluids dominated by salts other than $\mathrm{NaCl}$, although the derived parameter would be the activity of water in the salt solution, 
rather than salinity per se. Salinity could be modelled for this water activity based on an ion interaction model for a given solute.

Despite its inherently greater uncertainty relative to the estimation of salinity from final ice melting, there are a variety of situations where application of this method might be appropriate. It might be useful in cases where part of an inclusion population yield precise ice melting temperatures but where there is a transition into inclusions displaying vapour-absent metastability at low temperatures. Either the relationship presented here could be applied or, probably better, the $\mathrm{T}_{\mathrm{mf}}-\mathrm{T}_{\mathrm{mI}}$ relationship derived from the stable inclusions (assuming a sufficient number are available) could be used to predict salinity in the remaining, metastable inclusions. This would provide a test of whether the metastable inclusions were actually part of the same fluid inclusion assemblage or if they came from a different inclusion generation. In the former case, it would be better to use the salinities derived from ice melting to represent the salinity of the fluid inclusion assemblage.

One of the most useful applications of the method may be for the estimation of salinity in low temperature, liquid-vapor fluid inclusions in which the vapor bubble totally collapses on freezing. In such inclusions, the vapor bubble commonly does not renucleate prior to final ice melting or does so above the stable ice melting temperature, sometimes even above $0^{\circ} \mathrm{C}$ (e.g. Roedder, 1967b). These inclusions are in a metastable (vapor absent) state and so cannot be interpreted using the $\mathrm{NaCl}-\mathrm{H}_{2} \mathrm{O}$ binary or more complicated ternary phase diagrams. Artificial stretching is one way around this problem, but is unpredictable. However, metastable freezing occurs in the presence of vapor and is probably independent of vapor presence in any case; consequently, the metastable freezing method is probably the best way of estimating salinity in such inclusions.

In the future, it will be useful for researchers to collect metastable freezing data with associated relevant parameters such as inclusion size, cooling rate and presence of $\mathrm{CO}_{2}$ etc in order to build up a larger database on this behaviour in a broader range of inclusion types; this would increase confidence in the method and would help to better constrain the factors that lead to variability in the relationship between metastable freezing and salinity.

\section{Acknowledgments}

Thanks are due to Economic Geology reviewer Bob Bodnar for his helpful comments and Larry Meinert for editorial handling. Some of the data presented were collected as part of the NERCfunded Micro-to-Macro project GST/03/2653. This work was carried out in the fluid inclusion laboratory in the Department of Earth Science and Engineering at Imperial College London; departmental support for the facility is gratefully acknowledged.

\section{References}

Audétat, A., Günther, D., and Heinrich, C.A., 1998, Formation of a magmatic-hydrothermal ore deposit: Insights with LA-ICP-MS analysis of fluid inclusions: Science, v. 279, p. 2091-2279.

Audétat, A., Pettke, T., Heinrich, C.H., and Bodnar, R.J., 2008, The composition of magmatichydrothermal fluids in barren and mineralized intrusions: Economic Geology, v. 103, p. 877908.

Bloom, M.S., 1981, Chemistry of inclusion fluids; stockwork molybdenum deposits from Questa, New Mexico, Hudson Bay Mountain and Endako, British Columbia: Economic Geology, v. 76, p. 1906-1920. 
Bodnar, R.J., 1993, Revised equation and table for determining the freezing point depression of $\mathrm{H}_{2} \mathrm{O}-\mathrm{NaCl}$ solutions: Geochimica et Cosmochimica Acta, v. 57, p. 683-684.

Bodnar R.J., Lecumberri-Sanchez P., Moncada D., and Steele-MacInnis M., 2014, Fluid inclusions in hydrothermal ore deposits, in Holland H.D. and Turekian K.K., eds., Treatise on Geochemistry, Second Edition, Vol. 13: Oxford, Elsevier, p. 119-142.

Everett C.E., Wilkinson, J.J., and Rye, D.M., 1999, Fracture-controlled fluid flow in the Lower Palaeozoic basement rocks of Ireland: Implications for the genesis of Irish-type $\mathrm{Zn}-\mathrm{Pb}$ deposits, in McCaffrey, K.J.W., Lonergan, L., and Wilkinson, J.J., eds., Fractures, Fluid Flow and Mineralization: Geological Society of London, Special Publications 155, 247-276.

Gleeson, S.A., Wilkinson, J.J., Shaw, H.F., and Herrington, R.J., 2000, Post-magmatic hydrothermal circulation and the origin of base metal mineralization, Cornwall, UK: Journal of the Geological Society, London, v. 157, p. 589-600.

Heinrich, C.A., Günther, D., Audétat, A., Ulrich, T., and Frischknecht, R., 1999, Metal fractionation between magmatic brine and vapor determined by microanalysis of fluid inclusions: Geology, v. 27, p. 755-758.

Kanno, H., Miyata, K., Tomizawa, K., and Tanaka, H., 2004, Additivity rule holds in supercooling of aqueous solutions: Journal of Physical Chemistry A, v. 108, p. 6079-6082.

Koop, T., Luo, B., Tsias, A., and Peter, T., 2000, Water activity as the determinant for homogeneous ice nucleation in aqueous solutions: Nature, v. 406, p. 611-614.

Kouzmanov, K., and Pokrovski, G.S., 2012, Hydrothermal controls on metal distribution in porphyry $\mathrm{Cu}(-\mathrm{Mo}-\mathrm{Au})$ systems, in Hedenquist, J.W., Harris, M., and Camus, F., eds., Geology and Genesis of Major Copper Deposits and Districts of the World: Society of Economic Geologists, Special Publication 16, p. 573-618.

Lecumberri-Sanchez, P., Steele-MacInnis, M., and Bodnar, R.J., 2015, Synthetic fluid inclusions XIX. Experimental determination of the vapor-saturated liquidus of the system $\mathrm{H}_{2} \mathrm{O}-\mathrm{NaCl}-\mathrm{FeCl}_{2}$ : Geochimica et Cosmochimica Acta, v. 148, p. 34-49.

MacKenzie, A.P., Derbyshire, W., and Reid, D.S., 1977, Non-equilibrium freezing behaviour of aqueous systems: Philosophical Transactions of the Royal Society of London (Biological Sciences), v. 278, p. 167-189.

Mullin, J.W., 2001, Crystallization (4th Edition): Butterworth-Heinemann, Oxford, 600 p.

Rousseeuw, P.J. and Leroy, A.M., 1987, Robust regression and outlier detection: WileyInterscience, New York (Series in Applied Probability and Statistics), 329 p.

Roedder, E., 1967a, Fluid inclusions as samples of ore fluids, in Barnes, H.L., ed., Geochemistry of Hydrothermal Ore Deposits, 1 ${ }^{\text {st }}$ Edition: Holt, Rinehart and Winston, New York, p. 515-574.

Roedder, E., 1967b, Metastable superheated ice in liquid-water inclusions under high negative pressure: Science, v. 155, p. 1413-1417.

Roedder, E., 1984, Fluid Inclusions. Reviews in Mineralogy, Vol. 12: Mineralogical Society of America, Washington, DC, 646 p.

Roedder, E., and Bodnar, R.J., 1997, Fluid inclusion studies of hydrothermal ore deposits, in 
Barnes, H.L., ed., Geochemistry of Hydrothermal Ore Deposits (3rd Edition): Wiley, New York, p. 657-697.

Samson, I.M. and Russell, M.J., 1987, Genesis of the Silvermines zinc-lead-barite deposit, Ireland: Fluid inclusion and stable isotope evidence: Economic Geology, v. 82, p. 371-394.

Sellberg, J.A., Huang, C., McQueen, T.A., Loh, N.D., Laksmono, H., Schlesinge, D., Sierra, R.G., Nordlund, D., Hampton, C.Y., Starodub, D., DePonte, D.P., Beye, M., Chen, C., Martin, A.V., Barty, A., Wikfeldt, K.T., Weiss, T.M., Caronna, C., Feldkamp, J., Skinner, L.B., Seibert, M.M., Messerschmidt, M., Williams, G.J., Boutet, S., Pettersson, L.G.M., Bogan, M.J., and Nilsson, A., 2014, Ultrafast X-ray probing of water structure below the homogeneous ice nucleation temperature: Nature, v. 510, p. 381-384.

Shepherd, T.J., Rankin, A.H., and Alderton, D.H.M., 1985, A Practical Guide to Fluid Inclusion Studies: Blackie, Glasgow, 239 p.

Skinner, B.J., 1997, Hydrothermal mineral deposits: what we do and don't know, in Barnes, H.L., ed., Geochemistry of Hydrothermal Ore Deposits, 3rd Edition: Wiley, New York, p. 1-29.

Toner, J.D., Catling, D.C., and Light, B., 2014, The formation of supercooled brines, viscous liquids, and low-temperature perchlorate glasses in aqueous solutions relevant to Mars: Icarus, v. 233, p. 36-47.

Ulrich, T., Günther, D., and Heinrich, C.A., 1999, Gold concentrations of magmatic brines and the metal budget of porphyry copper deposits: Nature, v. 399, p. 676-679.

Wilkinson, J.J., 2001, Fluid inclusions in hydrothermal ore deposits: Lithos, v. 55, p. 229-272.

Wilkinson, J.J., 2010, A review of fluid inclusion constraints on mineralization in the Irish orefield and implications for the genesis of sediment-hosted $\mathrm{Zn}-\mathrm{Pb}$ deposits: Economic Geology, v. 105 , p. $417-442$.

Wilkinson, J.J., 2014, Sediment-hosted zinc-lead deposits: Processes and Perspectives, in Holland H.D. and Turekian K.K., eds., Treatise on Geochemistry, Second Edition, vol. 13: Oxford, Elsevier, p. 219-249.

Wilkinson, J.J., Everett, C.E., Boyce, A.J., Gleeson, S.A., and Rye, D.M., 2005, Intracratonic crustal seawater circulation and the genesis of sub-seafloor $\mathrm{Zn}-\mathrm{Pb}$ mineralization in the Irish orefield: Geology, v. 33, p. 805-808.

Wilkinson, J.J., Stoffell, B., Wilkinson, C.C., Jeffries, T.E., and Appold, M.S., 2009, Anomalously metal-rich fluids form hydrothermal ore deposits: Science, v. 323, p. 764-767.

$\mathrm{Xu}, \quad$ G., 2000, Fluid inclusions with $\mathrm{NaCl}-\mathrm{CaCl}_{2}-\mathrm{H}_{2} \mathrm{O}$ composition from the Cloncurry hydrothermal system, NW Queensland, Australia: Lithos, v. 53, p. 21-35.

Yardley, B.W.D., 2005, Metal concentrations in crustal fluids and their relationship to ore formation: Economic Geology, v. 100, p. 613-632. 


\section{Figure Captions}

Fig. 1. Uncontrolled cooling curve for the Linkam THMS600 heating-freezing stage using a LNP93 liquid nitrogen pump system set at maximum flow rate. The temperature window in which metastable freezing of aqueous fluid inclusions occurs is shown.

Fig. 2. Correlation between metastable freezing and final ice melting temperatures as recorded in this study. The best-fit line (all data) is a robust regression using the Least Median of Squares method which downweights outliers. The outliers shown (open symbols) were rigorously defined by the regression method. A bias of outliers towards the high $\mathrm{T}_{\mathrm{mf}} / \mathrm{low} \mathrm{T}_{\mathrm{mI}}$ side of the regression line is evident.

Fig. 3. Plot of metastable freezing against final ice melting temperatures subdivided according to host mineral. There is no obvious difference in behavior between inclusions hosted by the different minerals. The best-fit regression line for the entire dataset is shown.

Fig. 4. Plot of metastable freezing against final ice melting temperatures subdivided according to inclusion maximum dimension grouped into five bins of equal population size. There is no significant size effect on behavior, although a slight bias towards lower metastable freezing temperatures in the two largest inclusion size groups is apparent. The best-fit regression line for the subset of data for which size information was recorded is shown.

Fig. 5. Plot of metastable freezing against final ice melting temperatures highlighting $\mathrm{CO}_{2}$ bearing inclusions that form clathrate prior to metastable freezing. Some of these inclusions fall on the best-fit line for the entire dataset, but a significant proportion sits to the right of the line, interpreted to reflect anomalously early metastable freezing behavior due to the presence of $\mathrm{CO}_{2}$.

Fig. 6. Plot of metastable freezing against final ice melting temperatures subdivided according to heating-freezing stage model. There is no obvious difference in behavior between inclusions measured using the different systems.

Fig. 7. Metastable freezing data acquired from multiple runs on the same fluid inclusion using different cooling approaches. (1) free cooling from $25^{\circ} \mathrm{C}$; (2) free cooling from $0^{\circ} \mathrm{C}$; (3) cooling from $0^{\circ} \mathrm{C}$ at $50^{\circ} \mathrm{C} / \mathrm{min}$; and (4) cooling from $0^{\circ} \mathrm{C}$ at $20^{\circ} \mathrm{C} / \mathrm{min}$. The measured final ice melting temperature for this test inclusion was $-0.9^{\circ} \mathrm{C}$. Mean metastable freezing temperatures $\pm 1 \sigma$ are shown for each experiment.

Fig. 8. Tukey box-and-whisker plot illustrating the statistical distribution of replicate metastable freezing measurements recorded in the cooling rate experiments. The predicted freezing temperature for the inclusion used, based on the relationship between $\mathrm{T}_{\mathrm{mf}}$ and $\mathrm{T}_{\mathrm{mI}}$ developed in this study, is shown.

Fig. 9. Plot of final ice melting (open circles) and metastable freezing temperatures (filled circles) as a function of salinity derived from $\mathrm{T}_{\mathrm{mI}}$. Solid line represents the hypothetical homogeneous ice nucleation curve in solutions of variable salinity, where the effect of solutes is to depress the metastable freezing temperature at twice the rate of the depression of the ice melting temperature. The curve is offset from the ice melting curve at zero salinity, reflecting the supercooling "limit" of pure water $\left(\sim-38^{\circ} \mathrm{C}\right)$. The freezing data reported in this study track the theoretical curve quite closely with a scatter towards the "early freezing" side. Salinity values include data from the metastable extension of the ice liquidus. 
Fig. 10. Ice melting and metastable freezing as a function of solute concentration (A) and calculated water activity (B). Data trends shown in (A) were derived from 1-10 $\mu \mathrm{m}$ droplets of 18 different aqueous solutions $\left(\mathrm{H}_{2} \mathrm{SO}_{4}, \mathrm{HNO}_{3}\right.$, ternary $\mathrm{HNO}_{3} / \mathrm{H}_{2} \mathrm{SO}_{4}, \mathrm{NH}_{4} \mathrm{HSO}_{4},\left(\mathrm{NH}_{4}\right)_{2} \mathrm{SO}_{4}, \mathrm{NH}_{4} \mathrm{~F}$, $\mathrm{LiCl}, \mathrm{NaCl}, \mathrm{KCl}, \mathrm{NH}_{4} \mathrm{Cl}, \mathrm{CaCl}_{2}, \mathrm{MnCl}_{2}, \mathrm{Ca}\left(\mathrm{NO}_{3}\right)_{2}, \mathrm{H}_{2} \mathrm{O}_{2}$, urea, ethylene glycol, glycerol and glucose) using variable solute molality. When the metastable freezing data shown in (A) are presented in terms of water activity in each solution (mainly calculated using an ion interaction model) the data all collapse into the grey shaded field in (B) which can be fitted with a line of constant horizontal offset from the combined ice melting curve for various solutes (modified after Koop et al., 2000).

Fig. 1

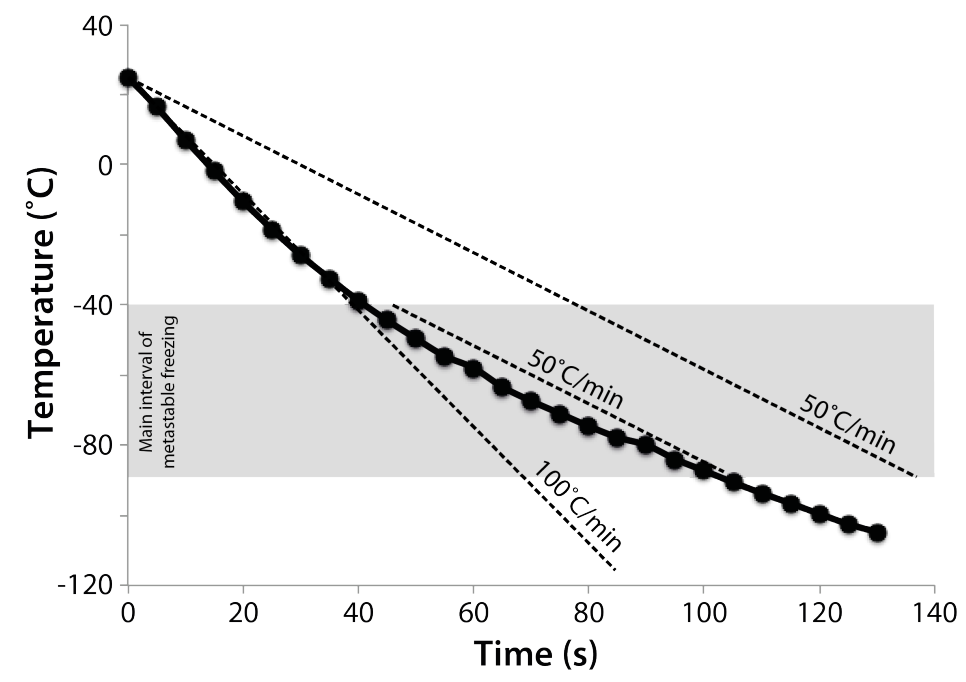

Fig. 2

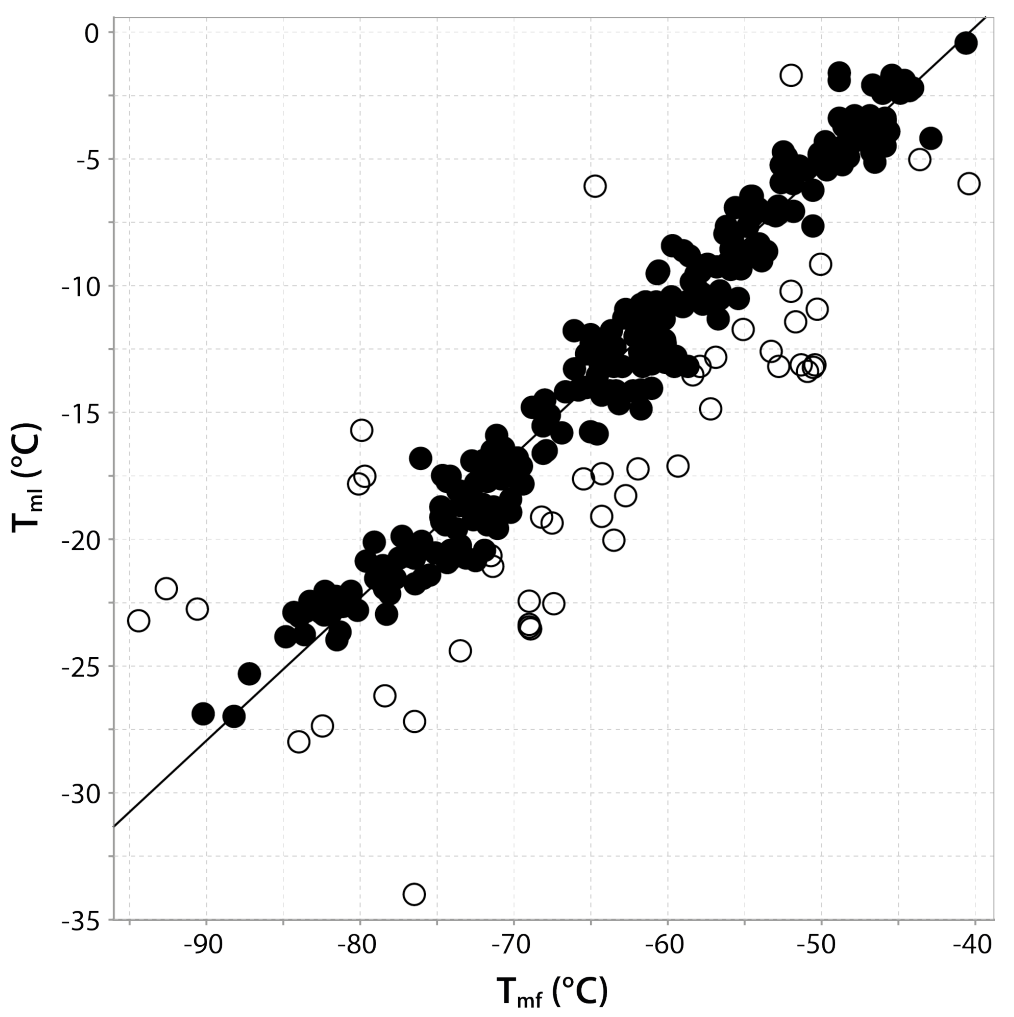


Fig. 3

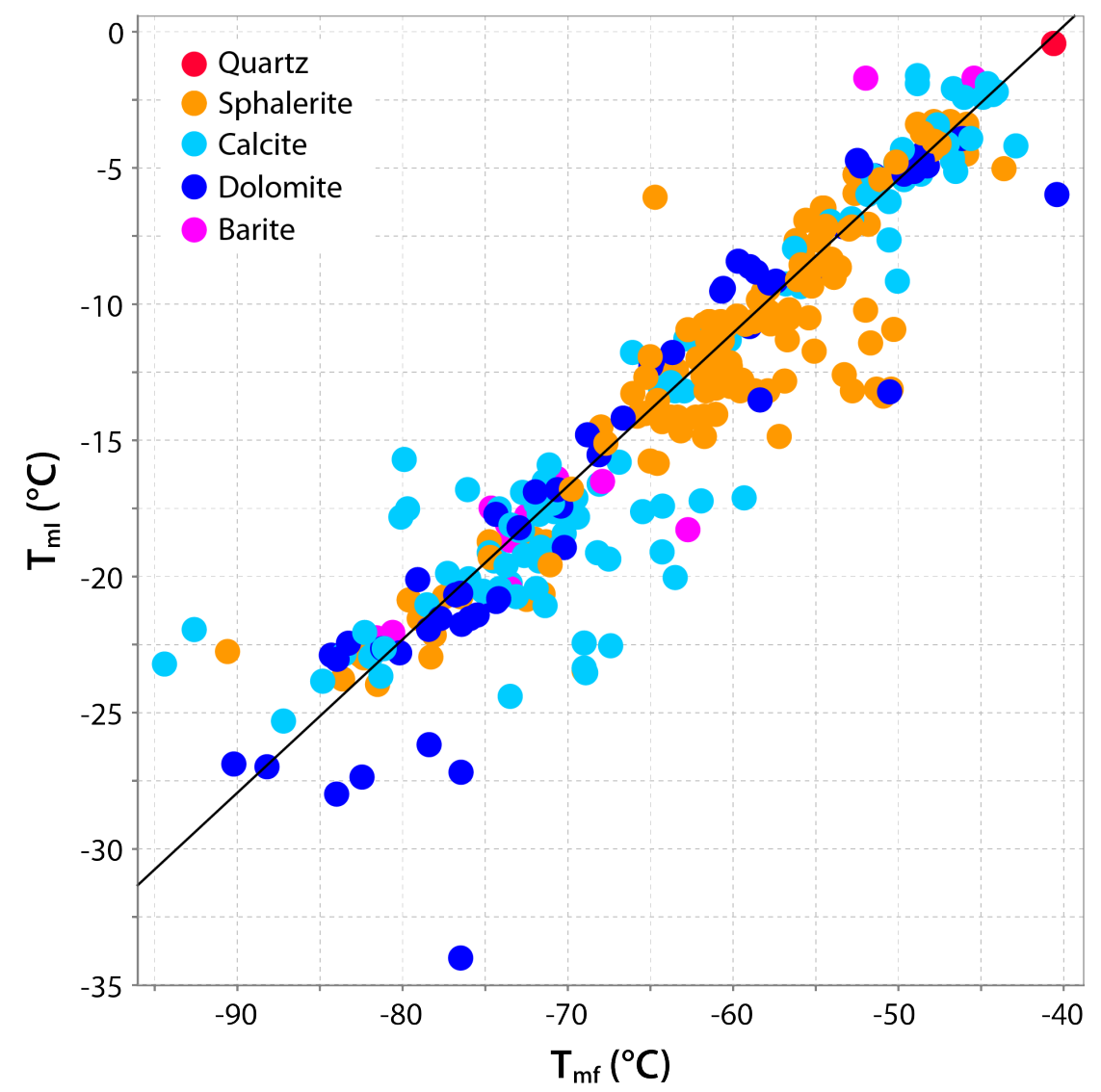

Fig. 4

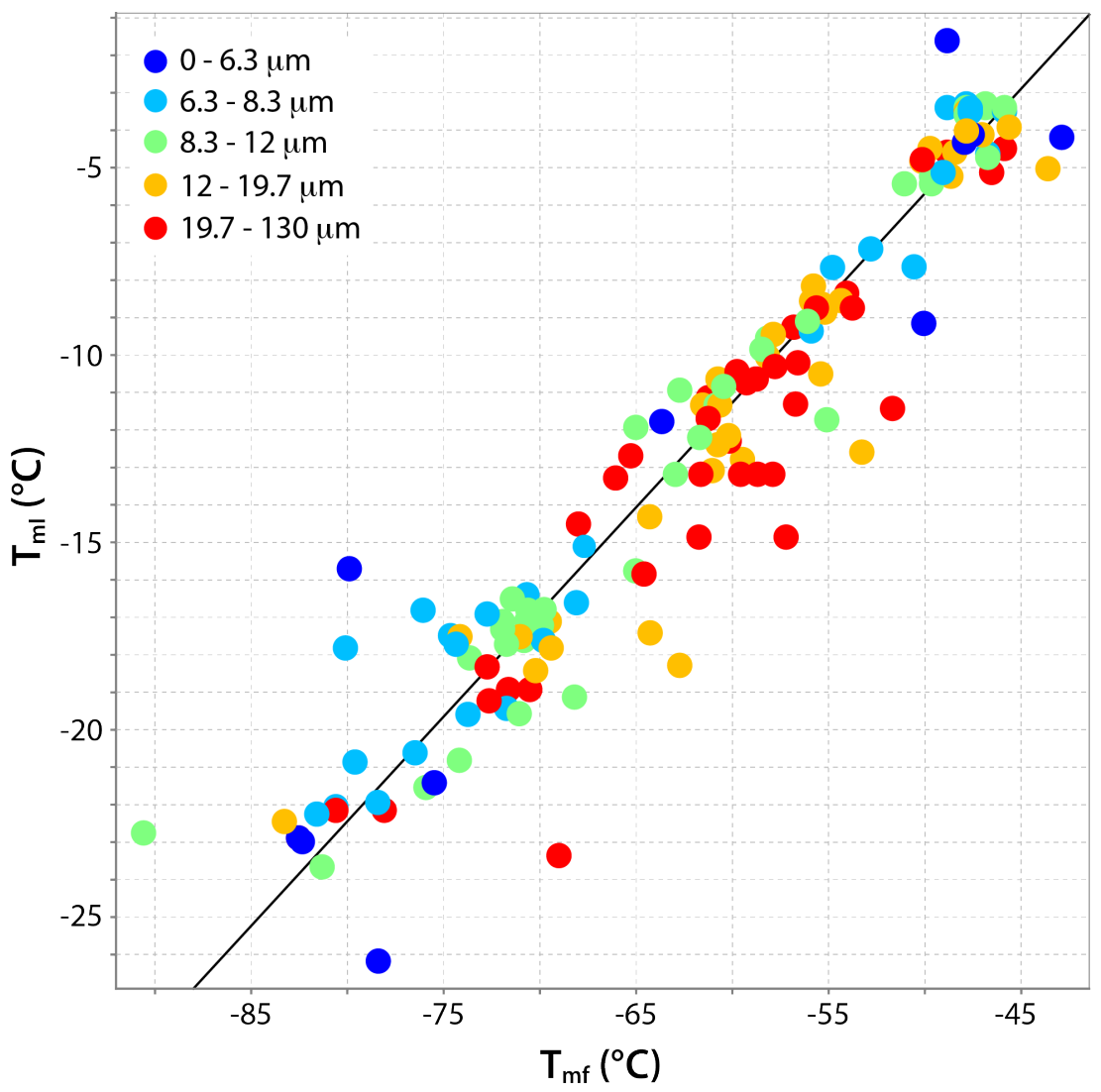


Fig. 5

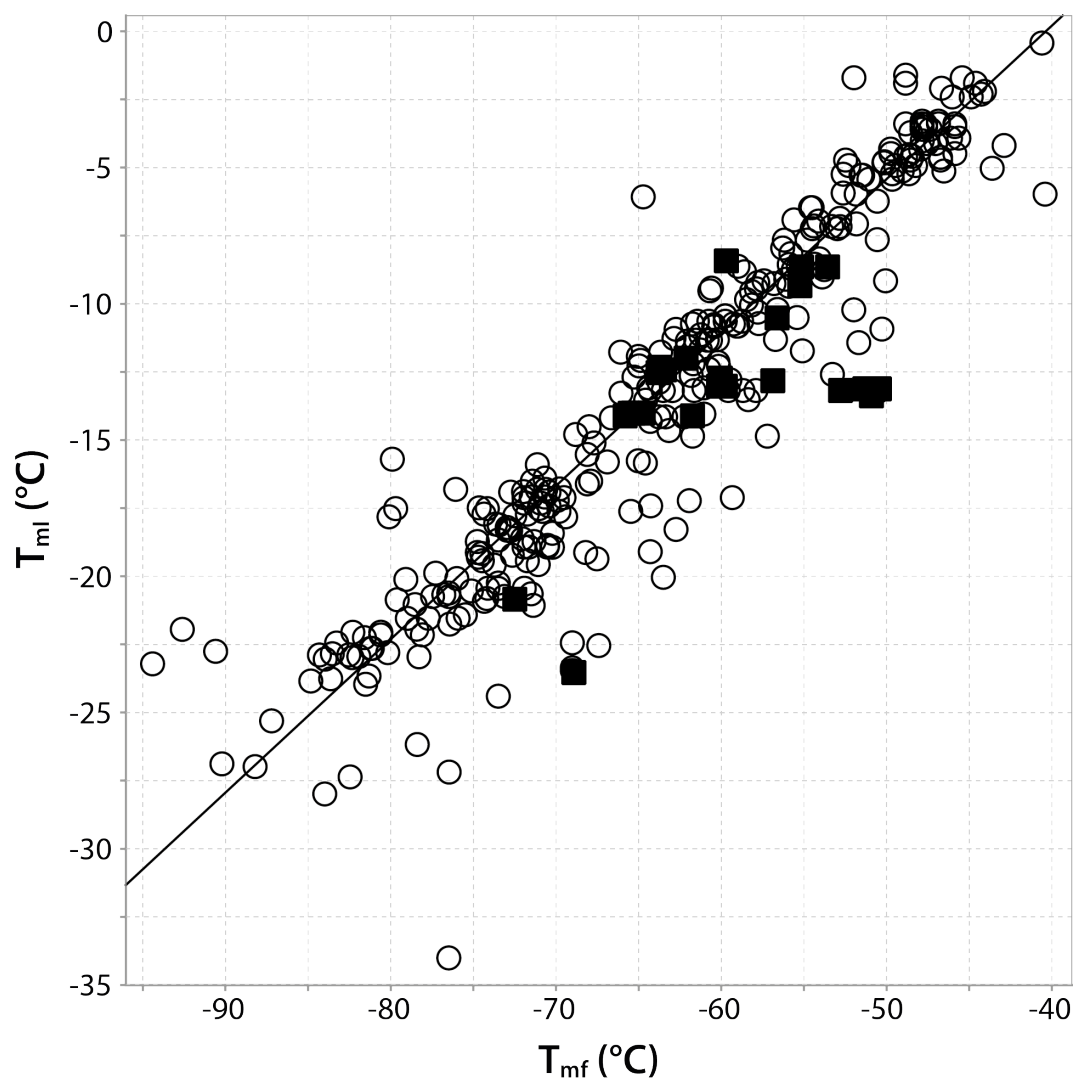

Fig. 6

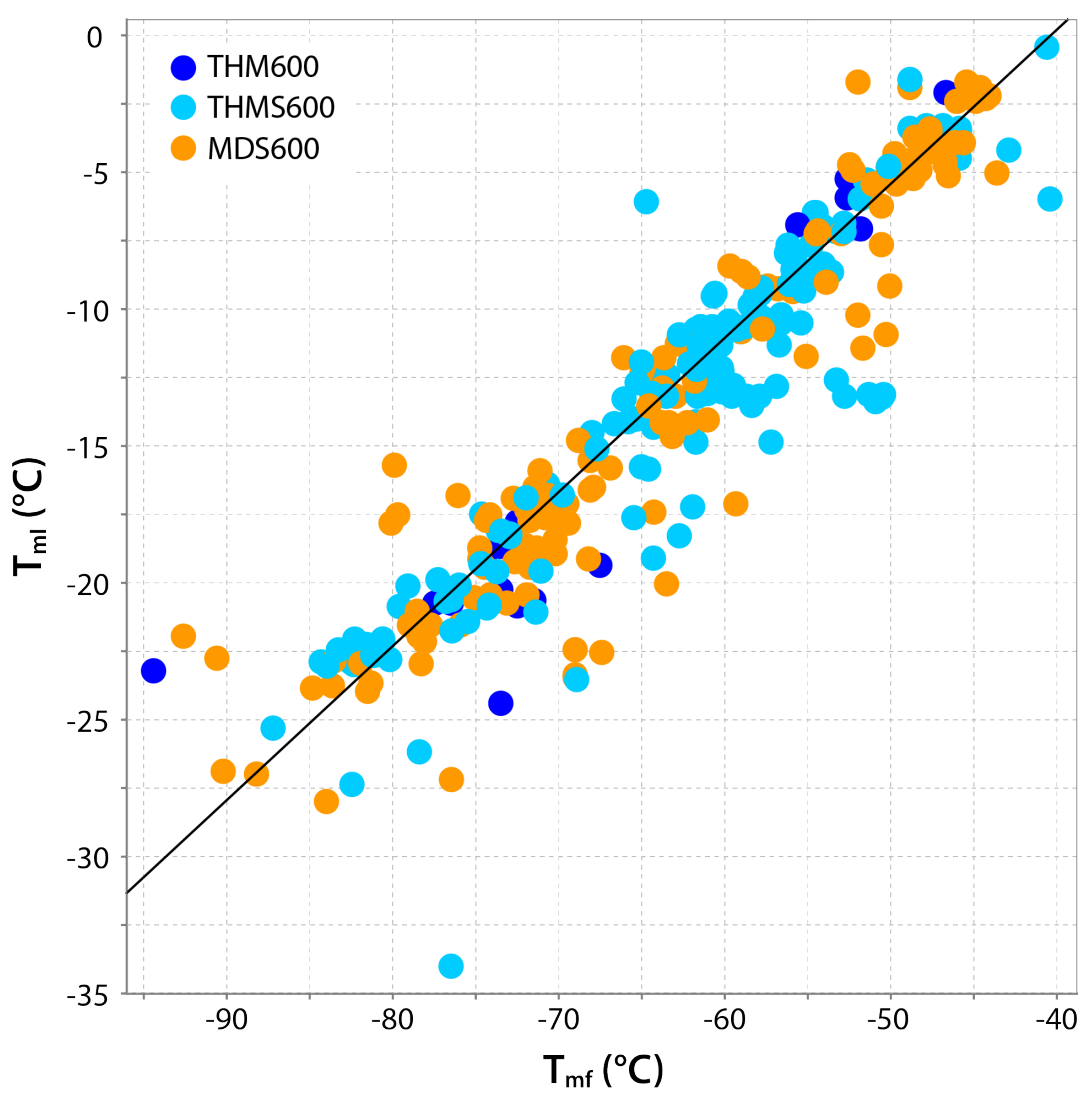


Fig. 7

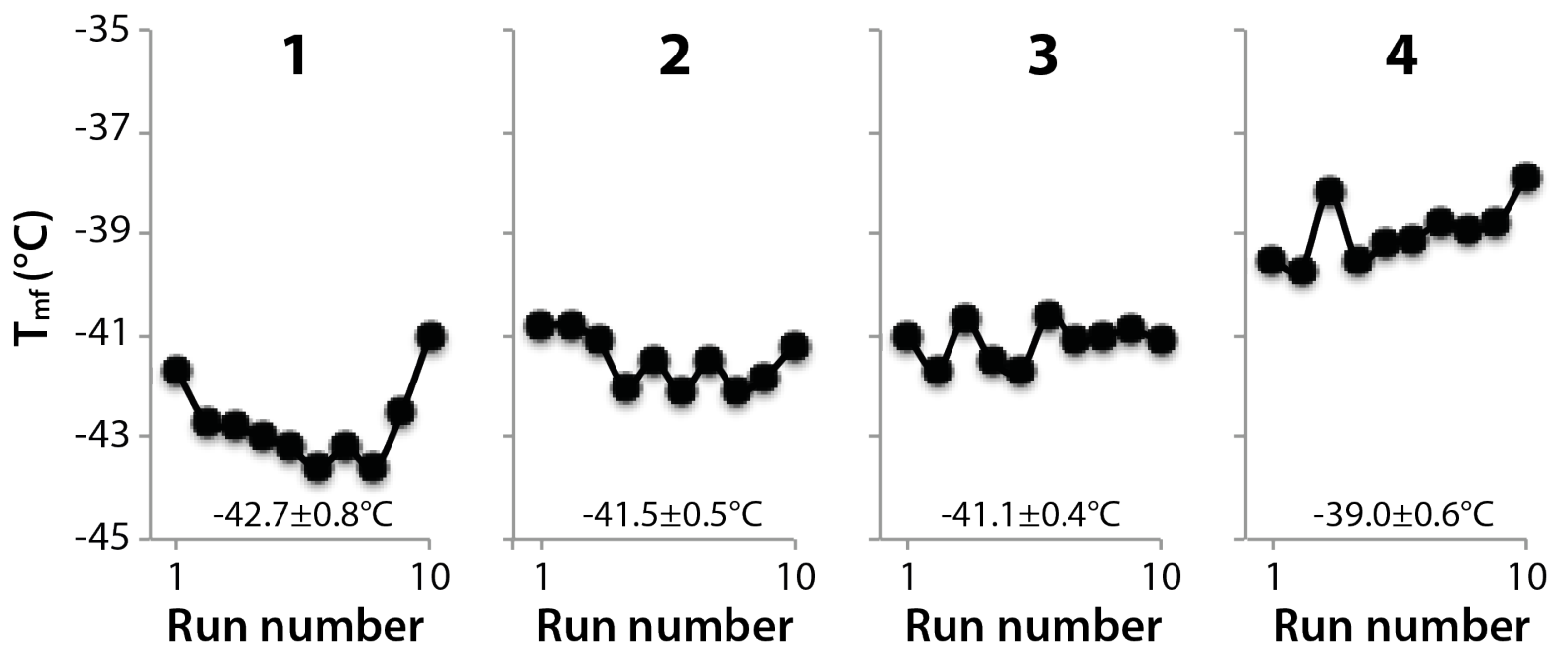

Fig. 8

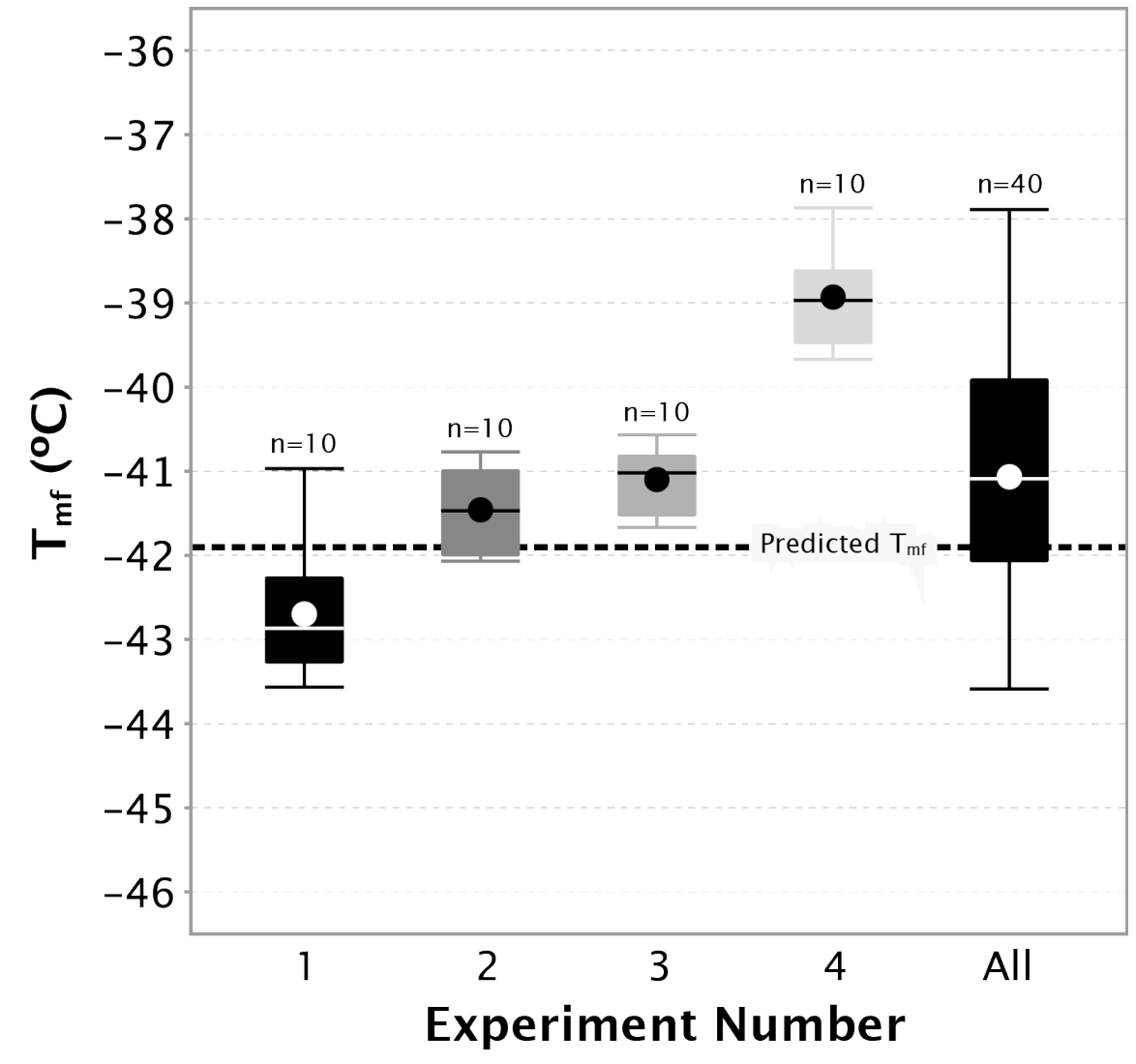


Fig. 9

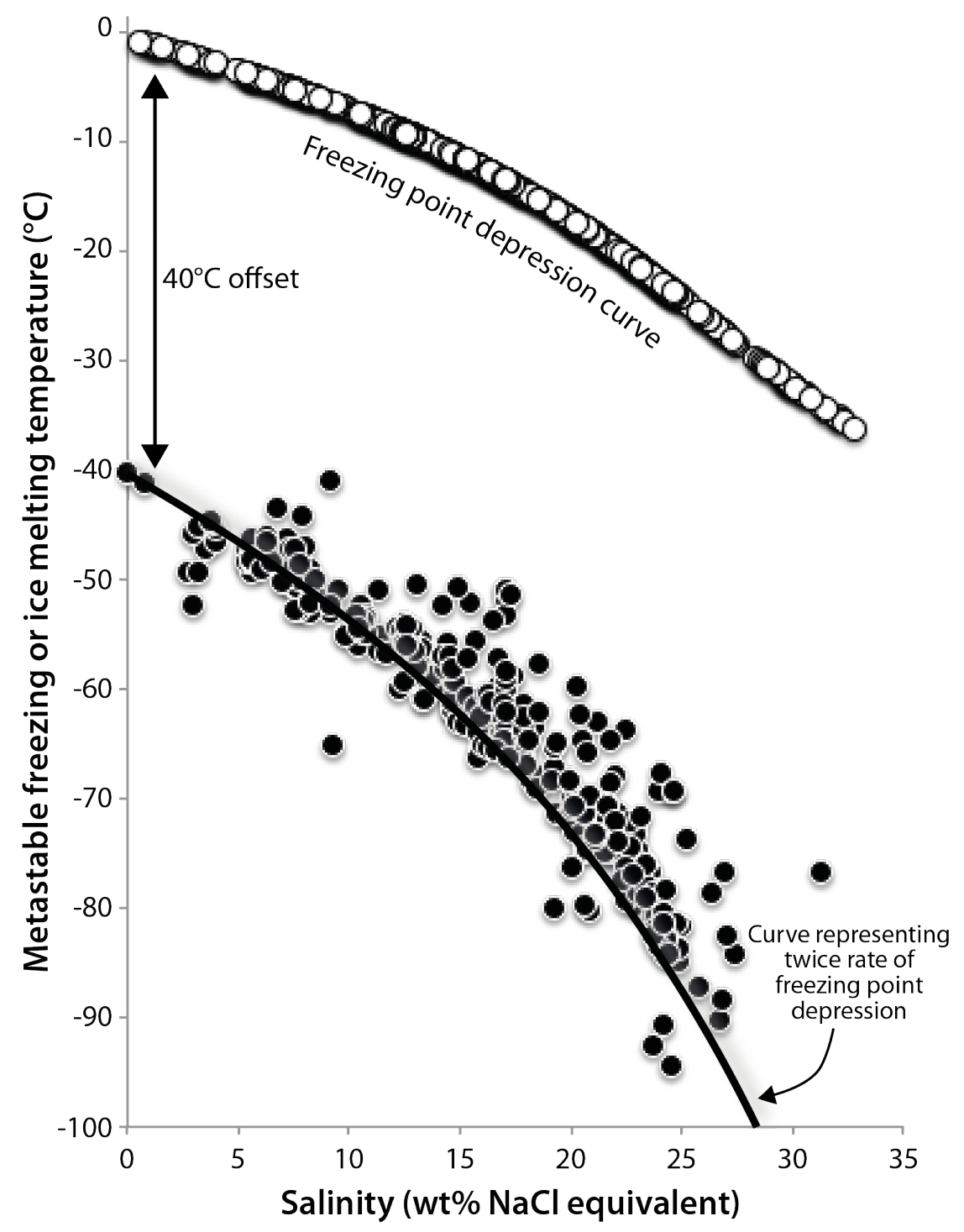

Fig. 10
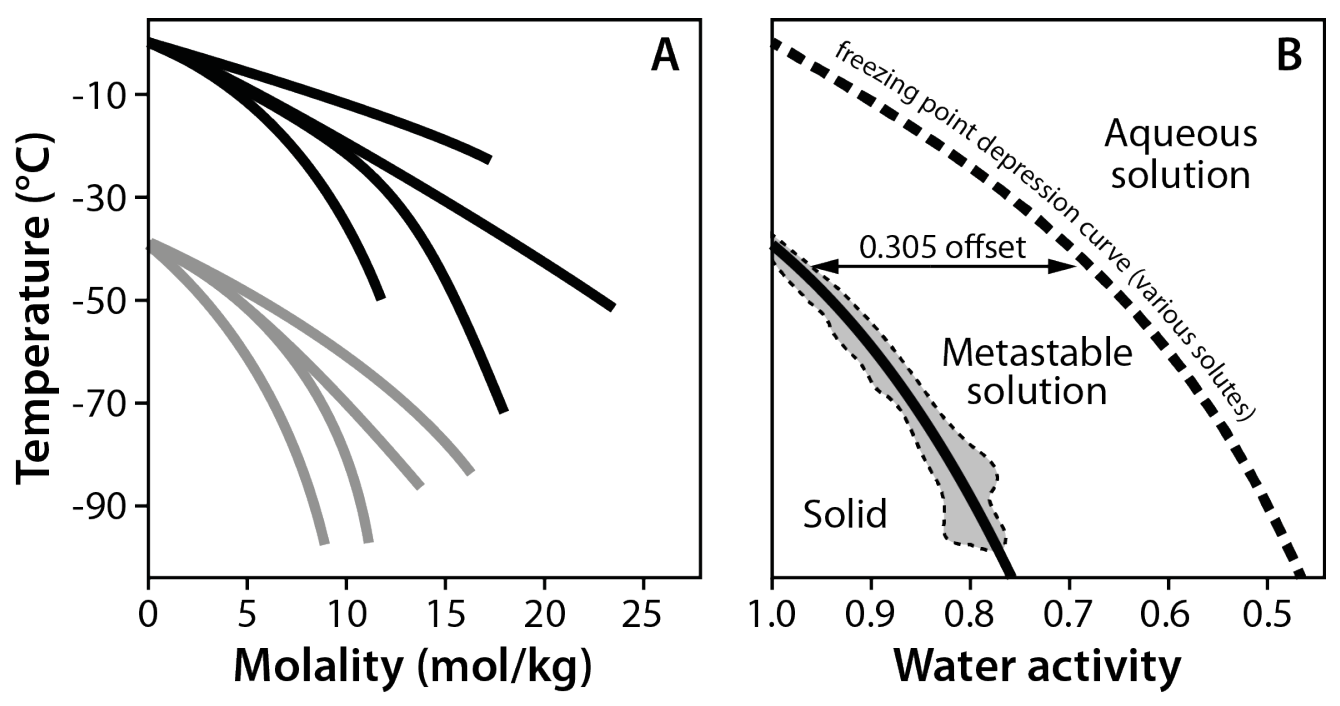